\title{
STUDI PERBANDINGAN HASIL BELAJAR PEMBELAJARAN 3X2 DENGAN 2X3 JAM PER-MINGGU SISWA SMA NEGERI 2 MATARAM
}

\author{
Syahrial ${ }^{1)}$, Wahyudi ${ }^{11}$, Gusti Afifah²) \\ 1)Program Studi Pendidikan Fisika, FKIP, Universitas Mataram, Mataram, NTB, Indonesia \\ ${ }^{2}$ SMA Negeri 2 Mataram, Pendidikan Fisika, Dikbud Propinsi NTB, Mataram, NTB, Indonesia \\ Corresponding author : \\ E-mail : syahrial_ayub@unram.ac.id
}

Diterima 19 September 2020, Direvisi 04 November 2020, Disetujui 05 November 2020

\begin{abstract}
ABSTRAK
Banyak faktor yang mempengaruhi hasil belajar, salah satunya adalah penggunaan cara belajar dan jam belajar. Kebiasaan siswa selalu memadatkan jam belajar terlebih saat akan menghadapi ujian. Jumlah jam belajar yang sama akan memberikan hasil yang berbeda tergantung pada cara penggunaannya. Permasalahannya adalah apakah terdapat perbedaan hasil belajar fisika antara kelas yang mendapat jam pembelajaran $2 \times 3$ dengan kelas yang mendapat jam pembelajaran $3 \times 2$ jam perminggu siswa kelas XI MIPA di SMA Negeri 2 Mataram. Penelitian ini bertujuan melihat perbedaan hasil belajar fisika siswa yang mendapat pembelajaran $3 \times 2$ jam perminggu dengan hasil belajar siswa yang mendapat pembelajaran $2 \times 3$ jam perminggu. Penelitian dilaksanakan pada kelas XI MIPA pada semester genap tahun pembelajaran 2020/2021. Jenis penelitian adalah penelitian eksperimen dengan sampel kelas XI MIPA 2 sebagai kelas eksperimen dan XI MIPA 4 sebagai kelas kontrol. Kelas eksperimen mendapat pembelajaran $3 \times 2$ jam perminggu dan kelas kontrol mendapat pembelajaran $2 \times 3$ jam perminggu. Hipotesis yang dikemukakan pada penelitian ini adalah hasil belajar fisika pembelajaran $3 \times 2$ jam perminggu lebih tinggi dibandingkan hasil belajar fisika pembelajaran $2 \times 3$ jam perminggu. Pengujian hipotesis dilakukan dengan t-tes pada taraf nyata $\alpha=0,05$ dengan derajat kebebasan $(\mathrm{dk})=$ 54 didapatkan $\mathrm{t}_{(0,95,54)}=1,67$, sedangkan thitung $=5,29$. Berarti dari hasil perhitungan thitung $>$ tabel, jadi hipotesis yang diajukan dapat diterima. Berdasarkan analisis penelitian ini disimpulkan bahwa hasil belajar fisika siswa yang mendapat pembelajaran $3 \times 2$ jam perminggu lebih baik dari pada hasil belajar siswa yang mendapat pembelajaran $2 \times 3$ jam perminggu.
\end{abstract}

Kata kunci: pembelajaran $3 \times 2$ dan 2×3 jam perminggu; studi perbandingan; hasil belajar.

\begin{abstract}
Many factors affect learning outcomes, one of which is the use of learning methods and learning hours. The habit of students always tightens their study hours, especially when facing exams. The same number of hours of study will produce different results depending on how it is used. The problem is whether there is a difference in physics learning outcomes between the class that gets $2 \times 3$ learning hours and the class that gets $3 \times 2$ hours of learning per week for class XI MIPA students at SMA Negeri 2 Mataram. This study aims to see the differences in the learning outcomes of students who get $3 \times 2$ hours of learning per week with the learning outcomes of students who get $2 \times 3$ hours of learning per week. The research was conducted in class XI MIPA in the even semester of the 2020/2021 learning year. This type of research is experimental research with a sample of class XI MIPA 2 as the experimental class and XI MIPA 4 as the control class. The experimental class got $3 \times 2$ hours of learning per week and the control class got $2 \times 3$ hours of learning per week. The hypothesis put forward in this study is that the learning outcomes of learning physics learning $3 \times 2$ hours per week are better than the learning outcomes of learning physics learning $2 \times 3$ hours per week. Hypothesis testing was carried out by t-test at the real level $\alpha=0.05$ with degrees of freedom $(\mathrm{dk})=54$, it was obtained $t_{(0,95,54)}=1.67$, while thitung $=5.29$. It means that the results of the calculation of thitung $>$ tabel, so the proposed hypothesis can be accepted. Based on the analysis of this research, it was concluded that the learning outcomes of students who got learning $3 \times 2$ hours per week were better than the learning outcomes of students who got learning $2 \times 3$ hours per week.
\end{abstract}

Keywords: learning $3 \times 2$ and $2 \times 3$ hours per week; comparative studies; learning outcomes 


\section{PENDAHULUAN}

Pembelajaran fisika masih didominasi oleh pembelajaran yang berpusat pada guru (teacher oriented) dan siswa kurang diberi kesempatan untuk mengembangkan kemampuan berpikir sehingga kegiatan pembelajaran masih kurang memfasilitasi siswa untu terlibat aktif dalam proses pembelajaran (Farizah, 2020). Fisika merupakan bagian dari ilmu yang pada hakekatnya merupakan kumpulan pengetahuan, cara berpikir, dan penyelidikan (Yuliatna, 2020). Saat ini, kita masih dihadapkan pada suatu kenyataan rendahnya mutu pendidikan dengan banyaknya siswa yang mendapatkan nilai rendah, khususnya matapelajaran fisika di SMA Negeri 2 Mataram. Sebagai gambaran, nilai rata-rata ujian nasional murni matapelajaran fisika di SMA Negeri 2 Mataram masih rendah. (Gusti Afifah, 2019) nilai rata-rata Ujian Nasional Murni SMA Negeri 2 Mataram Tahun Pembelajaran 2019/2020 adalah 45,11 (rentang skor 0 sd 100). Berbicara mengenai mutu banyak sekali faktor yang ikut terlibat, antara lain ketersediaan sarana prasarana, kurikulum, tenaga pengajar dan lingkungan belajar yang konstruktif. Kurikulum yang baik saja, belum menjamin diperolehnya hasil yang optimal tanpa dukungan tenaga pengajar yang baik, demikian pula sebaliknya. Syahrial Ayub (2019) mengatakan keberhasilan utama dari pembelajaran abad ini adalah bahwa siswa dianggap sebagai mitra yang bertindak dan berpikir, dan bukan diharapkan untuk menguasai dan menghapal pengetahuan yang tidak dia pahami. Salah satu aspek sarana pendidikan yang cukup penting adalah pemanfaatan waktu dalam proses pembelajaran. Abdullah Pandang (2013) mengatakan waktu belajar harus diatur dengan baik supaya mendapatkan hasil belajar yang maksimal. Masalah pengaturan waktu belajar merupakan masalah utama. Hasil wawancara dengan beberapa siswa di SMA Negeri 2 Mataram mendapatkan siswa SMA Negeri 2 Mataram banyak mengalami kesulitan dalam mengatur waktu belajar. Gusti Afifah (2020) dalam penelitiannya di SMA Negeri 2 Mataram menemukan terdapat hubungan yang berarti antara waktu belajar di luar jam sekolah dengan hasil belajar fisika siswa SMA Negeri 2 Mataram. Banyak siswa yang mengeluh kekurangan waktu dalam belajar baik itu di sekolah maupun di rumah, tetapi sesungguhnya mereka kurang memiliki keteraturan dan disiplin dalam mempergunakan waktunya. Banyak waktu seorang siswa terbuang dengan sia-sia terutama karena kebiasaan mengobrol atau melakukan kegiatan-kegiatan yang tidak bermanfaat.
Mengingat sangat pentingnya pengaturan waktu ini, perlu adanya kesungguhan dalam mengatur waktu belajar agar hasil yang dicapai dapat maksimal. Dalam hal ini, Hamalik Oemar (1998) mengemukakan tingkat penguasaan belajar tergantung pada waktu yang sebenarnya digunakan dalam belajar relatif terhadap waktu yang diperlukan. Sesuai dengan yang diuraikan di atas, maka dalam penyelenggaraan pendidikan dituntut penggunaan waktu yang efektif dan sebaik mungkin, agar waktu yang tersedia tidak hilang percuma tanpa mendapatkan hasil. Conny Setiawan (2000), mengatakan bahwa dalam merencanakan pembelajaran harus dipikir beberapa hal, sebagai berikut: siswa, waktu yang digunakan untuk pembelajaran, urutan materi, pengembangan proses berpikir, alat peraga dan penilain pembelajaran. Masalah masalah pokok yang dihadapi siswa tentang waktu belajar adalah: 1) kesukaran dalam pemakaian waktu, 2) ketidaktahuan mengenai ukuran-ukuran baku, dan 3) kebiasaan membaca yang lambat. Berdasarkan pendapat pendapat di atas dapat kita peroleh informasi bahwa masalah pokok yang dialami siswa dalam belajar adalah dalam hal penggunaan waktu belajar, hal ini akan mempengaruhi hasil belajar siswa. Kartini Kartono (2005) memaparkan belajar lebih efektif hasilnya dalam range waktu yang lebih pendek. Tingkat kosentrasi dalam belajar kurva naik sampai waktu 60 menit, lebih dari itu kurva akan turun, sedangkan waktu 15-25 menit pertama dapat digunakan mengarahkan kosentrasi ke materi yang disajikan. Relevan dengan pendapat di atas Slameto (2000) mengatakan waktu belajar cukup 2 jam untuk tiap belajar, bila lebih dari itu mungkin justru sudah tidak ada kosentrasi dalam belajar. Bertolak dari hal inilah, penulis ingin mengungkapkan tentang efektifitas jam belajar siswa kelas XI MIPA di SMA Negeri 2 Mataram. Jam pembelajaran akan dikondisikan untuk dua kelas sampel, yaitu kelas XI MIPA 2 dan XI MIPA 4. Kelas tersebut akan mendapatkan jumlah jam pembelajaran sama yaitu 6 jam pembelajaran tetapi dibedakan jumlah pertemuannya. Kelas XI MIPA 2 akan mendapat pertemuan 3 kali seminggu yang masing masing pertemuan dengan 2 jam pembelajaran. Kelas XI MIPA 4 mendapat pertemuan 2 kali seminggu yang masing masing pertemuan 3 jam pembelajaran. Pada penelitian sebelumnya Gusti Afifah (2020) mengungkapkan hubungan waktu belajar di luar jam sekolah dengan hasil belajar, sedangkan penelitian ini menyingkap efektifitas penggunaan waktu belajar di sekolah saat proses pembelajaran. Menjadi pertanyaan adalah apakah terdapat perbedaan hasil belajar 
fisika antara kelas yang mendapat jam pembelajaran $2 \times 3$ dengan kelas yang mendapat jam pembelajaran $3 \times 2$ jam perminggu siswa kelas XI MIPA di SMA Negeri 2 Mataram?

\section{METODE PENELITIAN}

Jenis penelitian yang digunakan adalah penelitian quasi eksperimen dengan desain untreated control group design with pretest and postest. Sebelum diberi perlakukan kedua kelompok sampel diberikan tes awal untuk mengukur kondisi awal (Nurhikmah, 2018). Instrumen atau alat pengumpul data pada penelitian ini adalah berupa tes hasil belajar tentang konsep fluida. $\mathrm{N}$ Desain penelitian dapat dilihat pada tabel 1 berikut ini (Sudjana, 2005):

Tabel 1 : Desain Penelitian

\begin{tabular}{lccc}
\hline \multicolumn{1}{c}{ Kelas } & Tes Awal & Perlakuan & Tes Akhir \\
\hline eksperimen & $\mathrm{T}_{\mathrm{e} 1}$ & $3 \times 2$ & $\mathrm{~T}_{\mathrm{e} 2}$ \\
kontrol & $\mathrm{T}_{\mathrm{k} 1}$ & $2 \times 3$ & $\mathrm{~T}_{\mathrm{k} 2}$ \\
\hline
\end{tabular}

dimana $\mathrm{T}_{\mathrm{e} 1}$ adalah tes awal pada kelas eksperimen, $T_{k 1}$ tes awal pada kelas kontrol, $T_{\mathrm{e} 2}$ adalah tes akhir pada kelas eksperimen dan $T_{k 2}$ tes akhir pada kelas kontrol. Perlakuan pembelajaran diberikan $3 \times 2$ jam perminggu pada kelas eksperimen dan $2 \times 3$ jam perminggu pada kelas kontrol. Sampel penelitian terdiri dari 56 orang, yang terdiri dari 2 kelas yaitu XI MIPA 2 dan XI MIPA 4 SMA Negeri 2 Mataram (Gusti Afifah, 2019). Rincian sampel dapat dilihat pada tabel 2 berikut ini:

\begin{tabular}{lccc}
\multicolumn{2}{c}{ Tabel 2 : Sampel Penelitian } \\
\hline Kelas & \multicolumn{2}{c}{ Banyak Siswa } & Jumlah \\
\cline { 2 - 3 } & Laki-Laki & Perempuan & \\
\hline XI MIPA2 & 20 & 6 & 26 \\
XI MIPA4 & 22 & 8 & 30 \\
\hline Jumlah & 42 & 14 & 56 \\
\hline
\end{tabular}

Tes awal pada kedua kelas sampel dilakukan uji F (uji homogenitas). Maksud uji F ini adalah untuk mengetahui kemampuan awal yang dimiliki siswa pada kedua kelas tersebut secara statistik. Hal ini penting dilakukan untuk memastikan hasil belajar yang didapat pada tes akhir memang benar akibat perlakuan yang diberikan bukan karena faktor lainnya. Perlakuan diberikan kepada kelas eksperimen (XI MIPA2) dengan pembelajaran 3x2 jam perminggu dan kelas kontrol (XI MIPA4) dengan pembelajaran $2 \times 3$ jam perminggu. Materi dan model pembelajaran pada kedua kelas dibuat sama hanya jam pembelajarannya saja yang dibedakan. Hasil tes akhir dilakukan uji-t untuk melihat perbedaan hasil belajar pembelajaran $3 \times 2$ dan $2 \times 3$ jam perminggu. Soal yang diberikan pada tes awal dan tes akhir adalah soal yang sudah di uji validitas, daya beda, indeks kesukaran dan reliabilitasnya.

\section{HASIL DAN PEMBAHASAN Tes Awal}

Hasil tes Awal pada kelas eksperimen dan kelas kontrol dapat dilihat pada tabel 3 berikut ini:

Tabel 3 : Hasil Tes Awal

\begin{tabular}{ccc}
\hline Statistik & \multicolumn{2}{c}{ Kelas } \\
\cline { 2 - 3 } & Eksperimen & Kontrol \\
\hline X $_{\text {rata-rata }}$ & 55,62 & 55,13 \\
$\mathrm{~s}$ & 10,58 & 12,85 \\
\hline $\mathrm{n}$ & 26 & 30 \\
\hline
\end{tabular}

setelah dilakukan pengolahan data didapatkan thitung untuk kelas eksperimen dan kontrol adalah 0,155 . Bila harga thitung dibandingkan dengan tabel $=2,00$, didapat thitung $<$ ttabel. Berdasarkan kriteria penolakan dan penerimaan hipotesis maka didapatkan kelas eksperimen dan kontrol memiliki kemampuan awal yang sama. Hal ini dapat dibuktikan dari hasil uji homogenitas varians skor tes awal, didapatkan $F_{h}=1,475$. Bila dibandingkan dengan $F_{\text {tabel }}$ untuk $\alpha=5 \%$ adalah 1,900. Maka $F_{h}<F_{\text {tabel }}$ sehingga dapat disimpulkan secara statistik skor tes awal homogen. Sebelum pengujian ini dilakukan, skor tes awal di uji normalitasnya pada taraf signifikansi $5 \%$ dan $\mathrm{dk}=5$, didapat seperti tabel 4 berikut ini :

Tabel 4 : Hasil Uji Normalitas

\begin{tabular}{lccc}
\hline \multicolumn{1}{c}{ kelas } & $\begin{array}{c}\chi^{2} \\
\text { hitung }\end{array}$ & $\begin{array}{c}\chi^{2} \\
\text { tabel }\end{array}$ & Kesimpulan \\
\hline eksperimen & 3,022 & 11,1 & Normal \\
kontrol & 4,621 & 11,1 & Normal \\
\hline
\end{tabular}

Data yang normal adalah data hasil belajar yang prosentase skor tinggi, skor rendah dan skor sedang mengikuti standar kurva normal seperti gambar 1 di bawah ini (Sudjana, 2005)

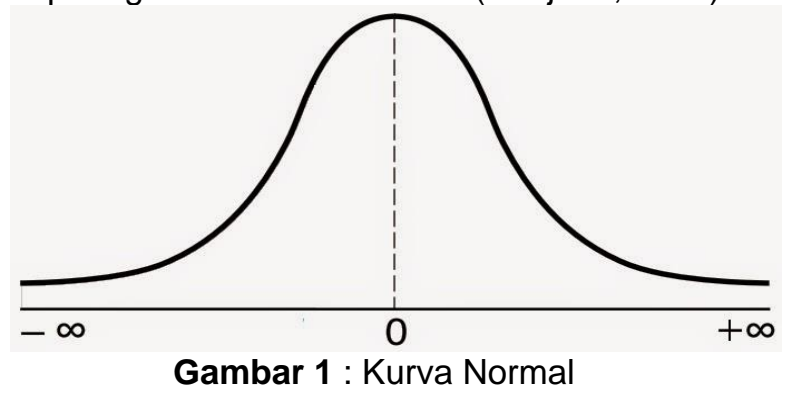

Secara sederhana, kurva normal adalah kurva yang berasal dari data-data yang terdistribusi normal. Ciri-ciri data terdistribusi normal terdapat keseimbangan simpangan antara sisi kiri dan sisi kanan, sehingga sigma total dari data keselurhan adalah nol. Kurva normal adalah suatu bentuk kurva yang sudah direncanakan, ordinatnya menunjukkan frekuensi dan poros absisnya memuat nilai 
variabel. Jika dilihat dari bentuknya, sudah bisa dipastikan bahwa disetiap ujung-ujungnya adalah distribusi atau sebaran dengan frekuensi (kemunculan) paling kecil. Sebaliknya, frekuensi yang paling banyak berada pada tengah-tengah kurva. Jadi sebuah data hasil belajar dikatakan normal bila siswa yang mendapat skor rendah dan tinggi hanya sebagian kecil saja yang banyak adalah siswa yang mendapat nilai sedang dengan prosentase seperti gambar 1 .

\section{Tes Akhir}

Hasil tes akhir pada kelas eksperimen dan kelas kontrol dapat dilihat pada tabel 5 berikut ini:

\begin{tabular}{ccc}
\multicolumn{3}{c}{ Tabel 5 : Hasil Tes Akhir } \\
\hline \multirow{2}{*}{ Statistik } & \multicolumn{2}{c}{ Kelas } \\
\cline { 2 - 3 } & Eksperimen & Kontrol \\
\hline X $_{\text {rata-rata }}$ & 52,97 & 39,42 \\
$\mathrm{~s}$ & 10,32 & 8,62 \\
\hline $\mathrm{n}$ & 26 & 30
\end{tabular}

Seperti yang dijelaskan sebelumnya, untuk melihat perbedaan hasil belajar fisika pada kelas eksperimen dan kelas kontrol digunakan statistik uji-t (t-test). Hasil belajar fisika yang diambil adalah hasil belajar dalam ranah kognitifnmya saja, yaitu mencakup kemampuan mengingat, menjelaskan, menerapkan, menganalisis, mengsintesis dan mengevaluasi termasuk di dalamnya kemampuan proses. Sebelum uji-t dilakukan terlebih dahulu dilakukan uji normalitas dan homogenitas dari data masing-masing kelas. Pada uji normalitas skor tes akhir kelas eksperimen didapat $\chi^{2}$ hitung $=6,330$. Untuk $\alpha=5 \%$ atau $\chi^{2} 0,95(5)=11,1$. Jadi dari hasil perhitungan didapatkan $\chi^{2}$ hitung $<\chi^{2}$ tabel berarti data terdistribusi normal. uji normalitas skor tes akhir kelas kontrol didapat $\chi^{2}$ hitung $=8065$. Untuk $\alpha=5 \%$ atau $\chi^{2} 0,95(5)=$ 11,1 . Jadi dari hasil perhitungan didapatkan $\chi^{2}$ hitung $<\chi^{2}$ tabel berarti data terdistribusi normal. Selanjutnya baru dilakukan t-tes pada kedua data di kelas eksperimen dan kelas kontrol. Perhitungan mendapatkan thitung $=5,29$ yang dibandingkan dengan harga persentil untuk taraf distribusi t dengan $\alpha=5 \%$ dan derajat kebebasan $(\mathrm{dk})=54$ diperoleh harga $\mathrm{t}_{(0,95,54)=}$ 1,67. Ternyata harga thitung $>$ tabel dengan demikian dapat disimpulkan terdapat perbedaan hasil belajar dari kedua kelas. Kelas eksperimen yang mendapat pembelajaran $3 \times 2$ jam perminggu mendapat hasil belajar yang lebih tinggi dari kelas kontrol yang mendapat pembelajaran $2 \times 3$ jam perminggu.

\section{Pembahasan}

Hasil penelitian mendapatkan pembelajaran dengan 3x2 jam perminggu mendapatkan hasil belajar fisika lebih baik dibandingkan pembelajaran $2 \times 3$ jam perminggu. Pembelajaran diberikan dengan jumlah jam yang sama, tetapi pada pembelajaran $3 \times 2$ dilakukan 3 kali pertemuan yang masingmasing pertemuan durasinya hanya 2 jam pembelajaran, sedangkan pembelajaran $2 \times 3$ dilakukan 2 kali pertemuan yang masing masing pertemuan 3 jam pembelajaran. Ternyata hasilnya berbeda, hal ini memberikan informasi kepada kita bahwa waktu belajar cukup 2 jam untuk tiap belajar. Bila lebih dari itu justru kurang kosentrasi dalam belajar. Hasil belajar dapat dicapai dengan baik, bila waktu belajar digunakan dengan efesien dan efektif. Di samping penggunaan waktu belajar yang efektif dan efesien ini, harus juga diperhatikan frekuensi pengulangan pelajaran. Belajar dipengaruhi oleh frekuensi perjumpaan dan lama waktu belajar. Pengulangan yang lebih sering dalam waktu yang lebih sedikit lebih baik dari pengulangan yang jarang dalam waktu yang lebih lama. Hal ini sama dengan banyaknya jam tatap muka di sekolah. Makin banyak jam tatap muka akan memberikan hasil yang lebih baik demikian pula sebaliknya. Seiring dengan analisis di atas di dapat dalam penelitian ini pembelajaran $3 \times 2$ jam perminggu lebih baik dari pembelajaran $2 \times 3$ jam perminggu yang mempengaruhi hasil belajarnya. Indah Lestari (2015) penelitiannya membuktikan terdapat pengaruh yang signifikan antara waktu belajar terhadap hasil belajar matematika. Hal ini menunjukan hasil belajar matematika akan meningkat bila siswa belajar pada waktu pagi hari. Materi pelajaran matematika yang sulit dan membutuhkan konsentrasi dalam mempelajarinya membutuhkan waktu yang tepat dalam belajar, kondisi waktu pagi hari yang masih segar karena belum banyak beraktifitas membantu siswa konsentrasi dalam belajar matematika, hal ini menyebabkan hasil belajar matematika meningkat. Bahwa waktu memang berpengaruh terhadap keberhasilan belajar seseorang (Hakim, 2005) seorang siswa akan dapat mencapai keberhasilan dalam belajar, jika ia memiliki waktu yang tepat untuk belajar dan bisa mengatur waktu tersebut agar lebih efisien sehingga proses pembelajaran lebih efektif. Hasil penelitian ini dapat diaplikasikan pada penelitian ini karena matematika merupakan bagian dari ilmu-ilmu MIPA. Nurita Juliasari (2016) menyimpulkan bahwa: (1) kecenderungan manajemen waktu belajar, motivasi belajar, fasilitas belajar, dan prestasi belajar matematika siswa SMP kelas VIII se-kecamatan Danurejan Yogyakarta berada pada kategori tinggi; (2) ada hubungan yang positif dan signifikan antara manajemen waktu belajar, motivasi belajar, dan fasilitas 
belajar dengan prestasi belajar matematika siswa SMP kelas VIII se-kecamatan Danurejan Yogyakarta. Berdasarkan hasil penelitian dan pembahasan dapat dipahami bahwa manajemen waktu belajar sangat penting dilakukan untuk mendapatkan hasil belajar yang optimal. Selanjutnya belajar dengan frekuensi yang sering akan lebih baik dari pada belajar dengan waktu yang lama dengan frekuensi yang sedikit.

\section{SIMPULAN DAN SARAN}

Berdasarkan data dan analisisnya maka dapat dikemukakan simpulan dan saran yang diharapkan bermanfaat bagi pembaca baik bidang studi fisika maupun bidang lainnya. Simpulan dari penelitian ini adalah: 1) terdapat perbedaan hasil belajar fisika antara siswa yang mendapat pembelajaran $3 \times 2$ dengan pembelajaran $2 \times 3$ jam perminggu, 2) hasil belajar fisika siswa yang mendapat pembelajaran $3 \times 2$ jam perminggu lebih baik dari hasil belajar siswa yang mendapat pembelajaran $2 \times 3$ jam perminggu. Saran peneliti adalah: 1) bagi guru diharapkan memperbanyak frekuensi tatap muka dengan siswa dalam proses pembelajaran karena pembelajaran yang dilakukan dengan cara ini akan membuat siswa bisa lebih kosentrasi. Sebaliknya bila pembelajaran yang kurang frekuensi tatap muka dengan melebihkan jam pembelajaran akan membuat siswa jenuh dan kurang kosentrasi. Akibatnya hasil belajar akan rendah, 2) pergunakanlah waktu belajar dengan sebaik dan se-efektif mungkin, karena penggunaan waktu belajar juga mempengaruhi hasil belajar siswa.

\section{UCAPAN TERIMA KASIH}

Terima kasih kami ucapkan kepada kepala sekolah dan guru di SMA Negeri 2 Mataram yang sudah memberikan izin kepada penulis untuk mengatur jam pembelajaran di kelaskelas yang menjadi sampel penelitian. Penelitian ini tidak akan bisa berjalan tanpa adanya izin yang diberikan ini, karena jam pembelajaran fisika di SMA tidak sesuai dengan keinginan penelitian sehingga memerlukan rekayasa waktu pembelajaran. Bagi guru-guru SMA N 2 Mataram yang jam pembelajarannya terganggu akibat penelitian ini, penulis mohon maaf dan mengucapkan terima kasih. Berikut LPPM Universitas Mataram yang telah memberikan fasilitas dan izin penelitian penulis juga mengucapkan terima kasih. Semoga ke depan kerjasama antara perguruan tinggi khususnya Universitas Mataram dengan sekolah-sekolah di Mataram bisa lebih meningkat dan berkualitas.

\section{DAFTAR RUJUKAN}

Abdullah, P. (2013). Manajemen Waktu Belajar. Universitas Negeri Makasar Press.

Ayub, S., Kosim, K., Gunada, I. W., \& Zuhdi, M. (2019). MODEL PEMBELAJARAN KESIAPSIAGAAN BENCANA GEMPABUMI DI SEKOLAH DASAR. ORBITA: Jurnal Kajian, Inovasi Dan Aplikasi Pendidikan Fisika. https://doi.org/10.31764/orbita.v5i2.118 7

Gusti, A. (2019). Laporan Pelaksanaan Ujian Nasional di SMA N 2 Mataram. SMAN2 Press.

Hakim, T. (2005). Belajar Secara Efektif. Pustaka Pembangunan Swadaya.

Hamalik, O. (1998). Metoda Belajar dan Kesulitan Belajar. Tarsito Bandung.

Juliasari, N., \& Kusmanto, B. (2016). HUBUNGAN ANTARA MANAJEMEN WAKTU BELAJAR, MOTIVASI BELAJAR, DAN FASILITAS BELAJAR DENGAN PRESTASI BELAJAR MATEMATIKA SISWA SMP KELAS VIII SE-KECAMATAN DANUREJAN YOGYAKARTA. UNION: Jurnal IImiah Pendidikan Matematika. https://doi.org/10.30738/.v4i3.435

Kartono, K. (2005). Bimbingan Belajar di SMA dan Perguruan Tinggi. Rajawali.

Lestari, I. (2015). Pengaruh Waktu Belajar dan Minat Belajar terhadap Hasil Belajar Matematika. Formatif: Jurnal IImiah Pendidikan MIPA. https://doi.org/10.30998/formatif.v3i2.1 18

Nurhikmah, N., Gunawan, G., \& Ayub, S. (2018). Pengaruh Model Pembelajaran Berbasis Masalah Berbantuan Simulation Based Laboratory (SBL) Terhadap Hasil Belajar Fisika Peserta Didik Kelas XI IPA SMAN 1 Montong Gading. Jurnal Pendidikan Fisika Dan Teknologi. https://doi.org/10.29303/jpft.v4i1.542

Sari, Y. (2020). Pengaruh Model Pembelajaran Kausalitik terhadap Kemampuan Pemecahan Masalah Fisika Peserta Didik. Jurnal GeoScienceEd Universitas Mataram, 1(1), 11-16.

Semiawan, C. (2009). Strategi Pengembangan Otak: Revolusi Biologi ke Revolusi Mental. Elex Media Komputindo.

Slameto, S. (2000). Faktor-Faktor yang Mempengaruhi Belajar. Tarsito Bandung.

Sudjana, S. (2005). Metoda Statistika. Tarsito Bandung.

Yulianti, F., Sutrio, S., \& Sahidu, H. (2020). PENGARUH MODEL GIVING QUESTION GETTING ANSWERS 
MELALUI METODE EKSPERIMEN TERHADAP MOTIVASI DAN HASIL BELAJAR FISIKA. ORBITA: Jurnal Kajian, Inovasi Dan Aplikasi Pendidikan Fisika.

https://doi.org/10.31764/orbita.v6i1.161 1 